\title{
ANALISIS FAKTOR-FAKTOR YANG MEMPENGARUHI KEUNGGULAN BERSAING TERHADAP KINERJA BISNIS (STUDI PADA UMKM BATIK DI KOTA SEMARANG)
}

\author{
Mohamad Ari Wibowo dan Susilo Toto Raharjo \\ Universitas Diponegoro (Undip) Semarang Jawa Tengah, Indonesia \\ Email: mohamadari849@gmail.com dan susilo_tr@yahoo.com
}

\section{Abstract}

This study examined the influence of factors that affect competitive advantages on business performance (Study on Batik MSMEs in Semarang City). Data obtained from the Office of Cooperatives and MSMEs semarang city recorded the number of batik MSMEs in the city of Semarang only 30. The problem becomes a serious problem because of the decrease in the number of MSMEs Batik and turnover every know, therefore it will be examined further. The purpose of this research is to analyze the influence of variables of entrepreneurial orientation, market orientation, intellectual capital, product innovation and competitive advantage on business performance. This study used a sample of all batik MSME owners in Semarang City. Purposive sampling method is used in this study as a method of data collection, the determination of the number of samples is 30 and 30 questionnaire forms collected from respondents as well as by interview techniques. The analysis technique used to analyze the data that has been obtained is structural equation mode partial least square (SEM-PLS) using AMOS application. All hypotheses in this study are. First, entrepreneurial orientation positively influences competitive advantage. second, market orientation positively affects the third competitive advantage, intellectual capital positively affects the competitive advantage. Fourth, product innovation does not have a positive effect on the competitive advantages of the five entrepreneurial orientations positively affect business performance. The six market orientations have no positive effect on business performance. The seven intellectual capitals have a positive impact on business performance. all eight product innovations have no positive effect on business performance. The nine competitive advantages positively affect business performance.

Keywords: entrepreneurial orientation; market orientation; intellectual capital; product innovation; competitive advantage; business performance

\section{Abstrak}

Penelitian ini meneliti mengenai pengaruh dari faktor-faktor yang mempengaruhi Keunggulan bersaing terhadap Kinerja Bisnis (Studi Pada UMKM Batik di Kota Semarang). Data yang diperoleh dari Dinas Koperasi dan UMKM Kota Semarang mencatat jumlah UMKM batik di Kota Semarang hanya 30. Permasalahan tersebut menjadi masalah yang cukup serius karena menurunya jumlah UMKM Batik dan omzet setiap tahunya, oleh karena itu akan di teliti lebih lanjut. Tujuan

$\begin{array}{ll}\text { How to cite: } & \text { Wibowo, Mohamad Ari dan Susilo Toto Raharjo (2021) Analisis Faktor-Faktor Yang Mempengaruhi } \\ & \text { Keunggulan Bersaing Terhadap Kinerja Bisnis (Studi Pada Umkm Batik di Kota Semarang). Syntax } \\ & \text { Literate. 6(5). http://dx.doi.org/ 10.36418/syntax-literate.v6i5.2412 } \\ \text { E-ISSN: } & \text { 2548-1398 } \\ \text { Published by: } & \text { Ridwan Institute }\end{array}$


dilakukannya penelitian ini adalah untuk menganalisis pengaruh dari variabel orientasi kewirausahaan, orientasi pasar, intellectual capital, inovasi produk dan keunggulan bersaing terhadap kinerja bisnis. Penelitian ini menggunakan sampel semua pemilik UMKM Batik di Kota Semarang. Metode purposive sampling digunakan dalam penelitian ini sebagai metode pengumpulan data, penentuan jumlah sampel adalah 30 dan 30 form kuesioner terkumpul dari responden serta dengan teknik wawancara. Teknik analisis yang digunakan untuk menganalisis data yang telah diperoleh adalah dengan teknik Structural Equation Mode partial least square (SEM-PLS) dengan menggunakan aplikasi AMOS. Seluruh hipotesis pada penelitian ini yakni. Pertama, orientasi kewirausahaan berpengaruh positif keunggulan bersaing. kedua, orientasi pasar berpengaruh positif terhadap keunggulan bersaing ketiga, intellectual capital berpengaruh positif terhadap keunggulan bersaing. Keempat, inovasi produk tidak berpengaruh positif terhadap keunggulan bersaing kelima orientasi kewirausahaan berpengaruh positif terhadap kinerja bisnis. Keenam orientasi pasar tidak berpengaruh positif terhadap kinerja bisnis. Ketujuh intellectual capital berpengaruh positif terhadap kinerja bisnis. kedelapan inovasi produk tidak berpengaruh positif terhadap kinerja bisnis. Kesembilan keunggulan bersaing berpengaruh positif terhadap kinerja bisnis.

Kata Kunci: orientasi kewirausahaan; orientasi pasar; intellectual capital; inovasi produk; keunggulan bersaing; kinerja bisnis

\section{Pendahuluan}

Keunggulan kompetitif meningkat dari nilai yang diciptakan perusahaan untuk pelanggannya dan bukan biaya yang dikeluarkan oleh perusahaan untuk menciptakannya. Nilai atau manfaat semacam ini akan dibayarkan oleh pelanggan lain, dan nilai superior yakni penetapan harga lebih rendah dibandingkan dengan harga pesaing (Porter, 1985). (Tubagus Ismail, 2012) menyatakan bahwa perusahaan atau organisasi yang memproduksi barang atau jasa tentunya wajib memperhatikan konsep keunggulan kompetitif, agar perusahaan atau organisasi dapat bertahan dan sebagai imbalannya akan mencapai keuntungan. Hall (1990) mengungkapkan bahwa keunggulan kompetitif terdapat tiga dimensi: daya tahan lama, sulit ditiru, dan mudah identik.

Keunggulan kompetitif akan meningkatkan kinerja bisnis UKM melalui pertumbuhan laba, pertumbuhan penjualan, dan pertumbuhan pelanggan. Hasilnya (Chan, Shaffer, \& Snape, 2004) menyatakan bahwa keunggulan kompetitif secara positif mempengaruhi kinerja perusahaan. Indikator kinerja bisnis UKM (Stamp, 2008), adalah pengukuran pengembangan penjualan, pengembangan pelanggan, pengembangan laba dan pengembangan modal kerja yang sangat penting bagi mereka seperti finansial dan waktu untuk melakukan pekerjaan yang ternyata tidak sesuai dengan tujuan perusahaan. UKM perlu merumuskan suatu strategi untuk membuat bisnisnya ada pada track yang benar untuk pencapaian tujuan UKM yaitu kinerja bisnis yang prima. Masalah mendasar dari manajemen strategi adalah bagaimana suatu organisasi dapat mencapai kinerja yang unggul dan mempertahankan keunggulan kompetitif yang berkelanjutan (Teece, Pisano, \& Shuen, 1997). Namun, sumber daya 
yang dimiliki oleh organisasi, jika terlalu mudah bagi pesaing untuk meningkatkan dan menciptakan sumber daya pengganti yang lebih efektif, bukanlah faktor utama untuk mencapai keunggulan kompetitif yang berkelanjutan. (Hsu, Ju, Yen, \& Chang, 2007) dan (Chowdhury, 2013) mendefinisikan bahwa, semakin mudah teknologi ditiru; dengan perubahan cepat dari pesaing dan aturan masyarakat; semakin banyak pengetahuan organisasi muncul sebagai sumber utama keunggulan kompetitif. Studi oleh (Rodan, 2008) pada pandangan berbasis sumber daya menekankan bahwa pengetahuan strategis berbasis sumber daya menjadi berpengaruh terhadap strategi bisnis. Hasil studi ini memiliki kesamaan dan memperkuat penelitian sebelumnya (Budiastuti \& Versia, 2011) adanya pengaruh yang signifikan antara keunggulan bisnis terhadap kinerja bisnis. Hasil studi menguatkan temuan penelitian (Daud Ismail, Alam, \& Hamid, 2017) bahwa kinerja ekspor dimediasi keunggulan kompetitif. Hasil ini berkebalikan dengan penelitian (Echdar, 2012), dan (Asyhari, Pudjihastuti, \& Kurdaningsih, 2018) yang menemukan bahwa kinerja berdampak positif serta signifikan terhadap keunggulan kompetitif. Dalam penelitian ini adalah kinerja perusahaan atau kinerja bisnis adalah kinerja keuangan yang dicapai dalam bentuk pencapaian dari aspek keuangan oleh UKM. Kinerja perusahaan adalah tingkat keberhasilan perusahaan dalam mencapai tujuannya melalui penggunaan berbagai sumber daya yang dimilikinya. Baik buruknya kinerja perusahaan sangat dipengaruhi oleh kemampuan perusahaan untuk menggunakan sumber dayanya dan beradaptasi dengan perubahan kondisi inovasi. (Ismanu \& Kusmintarti, 2018) menyatakan bahwa pengukuran kinerja perusahaan dapat dilihat dari tingkat penjualan, profitabilitas, pengembalian modal, tingkat turnover, dan pangsa pasar. Kinerja dalam penelitian ini diukur dengan tingkat indikator produksi, pangsa pasar yang dicapai oleh volume penjualan yang tinggi dan profitabilitas UKM yang diperoleh.

Jumlah UKM di Indonesia sekarang ini jumlah semakin bertambah. UKM di Indonesia juga menyumbang total $60 \%$ dari pertumbuhan ekonomi nasional (Bank Indonesia, 2018). Hal ini juga kontras dengan pertumbuhan jumlah UKM, pertumbuhan penyerapan tenaga kerja dan pertumbuhan omset UKM khususnya di Jawa Tengah. Data UKM Binaan Provinsi Jawa Tengah dapat dilihat dalam table sebagai berikut:

Tabel 1

Data UKM Binaan Provinsi Jawa Tengah

\begin{tabular}{llllllll}
\hline No & Deskripsi & Satuan & Tahun & & & \\
\cline { 4 - 7 } & & & $\mathbf{2 0 1 3}$ & $\mathbf{2 0 1 4}$ & $\mathbf{2 0 1 5}$ & $\mathbf{2 0 1 6}$ & $\mathbf{2 0 1 7}$ \\
\hline 1 & Jumlah UKM & Unit & 90.339 & 99.681 & 108.937 & 115.751 & 133.679 \\
\hline 2 & $\begin{array}{l}\text { Penyerapan } \\
\text { tenaga kerja }\end{array}$ & Orang & 480.508 & 608.893 & 740.740 & 791.767 & 918.455 \\
\hline 3 & Omzet & $\begin{array}{l}\text { Rp. } \\
\text { Milyar }\end{array}$ & 20.345 & 24.587 & 29.113 & 43.570 & 49.247 \\
\hline
\end{tabular}

Sumber : Dinas Koperasi dan UKM Provinsi Jawa Tengah, 2019

Berdasarkan data yang ada, dapat diketahui bahwa terdapat pertumbuhan yang terus menerus dari UKM yang ada di Jawa Tengah selama periode 2013-2017. Hasil ini 
menunjukkan bahwa secara umum UKM di wilayah Jawa Tengah mengalami peningkatan kinerja bisnisnya. Namun demikian, selama periode 2013- 2017, terapat sektor UKM yang mengalami penurunan yaitu pada UKM Batik dengan data sebagai berikut:

Tabel 2

Data UKM Batik Kota Semarang

\begin{tabular}{llllllll}
\hline No & Deskripsi & Satuan & \multicolumn{2}{l}{ Tahun } & & \\
\cline { 3 - 7 } & & & $\mathbf{2 0 1 3}$ & $\mathbf{2 0 1 4}$ & $\mathbf{2 0 1 5}$ & $\mathbf{2 0 1 6}$ & $\mathbf{2 0 1 7}$ \\
\hline 1 & Jumlah UKM & Unit & 100 & 70 & 65 & 50 & 30 \\
\hline 2 & $\begin{array}{l}\text { Penyerapan } \\
\text { tenaga kerja }\end{array}$ & Orang & 1855 & 1598 & 1135 & 975 & 787 \\
\hline 3 & Omzet & Rp. Milyar & - & -14 & -29 & -14 & -19 \\
\hline
\end{tabular}

Permasalahan yang ada adalah pada periode 2013-2017, diketahui bahwa terjadi penurunan omset dari UKM Batik di Kota Semarang pada periode 2013-2017, tentunya berbanding terbalik dengan peningkatan jumlah UKM yang bergerak di sektor Batik. Hal ini menunjukkan bahwa terdapat permasalahan pada UKM sektor Batik di Kota Semarang. Penurunan kinerja bisnis UKM sektor Batik di Kota Semarang ini diduga disebabkan karena kurangnya strategi bisnis yang dimiliki oleh UKM sektor Batik di Kota Semarang sehingga kinerja bisnisnya tidak maksimal. Strategi bisnis berkaitan dengan perencanaan dan arahan yang akan dicapai oleh perusahaan dalam suatu periode waktu dimana perusahaan akan menyesuaikan diri dengan sumber-sumber daya yang dimilikinya dan melakukan langkah-langkah untuk lebih meningkatkan kinerja bisnis perusahaan.

\section{Metode Penelitian}

Objek atau sampel dalam penelitian ini adalah adalah pemilik atau yang bertanggung jawab dalam kegiatan UMKM Batik yang berada di Kota Semarang yang berjumlah berjumlah 30 orang, yang diperoleh dari hasil penentuan sampel dengan metode sampling sensus, yaitu sampel yang digunakan adalah keseluruhan jumlah populasi.

Pada penelitian ini teknik yang digunakan, dilakukan dengan metode kuesioner dan wawancara. Kuesioner tersebut berisi angket berisi pernyataan dan dapat dipilih langsung oleh responden, bertujuan agar peneliti mendapatkan data yang diharapkan dan wawancara. Metode pengumpulan data ini dilakukan untuk mengumpulkan data primer.kuantitatif digunakan untuk menjelaskan data kualitatif. Data kualitatif ini didapatkan melalui wawancara dengan partisipan secara mendalam (Sugiyono, 2015).

Instrument yang digunakan dalam mengumpulkan data adalah metode kuesioner dengan menggunakan skala tipe likert (likert scale). Masing-masin pertanyaan dari kuesioner memiliki 5 (lima) skala dimana angka 1 pada sebelah kiri menunjukkan jawaban sangat tidak setuju dari pertanyaan dan pernyataan yang terdapat pada kuisioner. Sebaliknya angka 5 pada sebelah kanan menunjukkan angka jawaban dari responden yang memiliki penilaian positif atau sangat setuju dengan pertanyaan atau pernyataan yang diajukan . 
Penentuan variabel dan indikator secara keseluruhan yang digunakan dalam penelitian ini dapat dilihat pada Tabel 3 yaitu sebagai berikut:

\section{Tabel 3}

Definisi Operasional Variabel

\begin{tabular}{cll}
\hline Variabel & \multicolumn{1}{c}{ Definisi Operasional Variabel } & Indikator \\
\hline & Faktor yang dapat meningkatkan kinerja bisnis menjelaskan & OK1 : Proaktif \\
Orientasi & bahwa karakteristik orientasi kewirausahaan diamati dari & OK2 : Otonomi \\
Kewirausahaan & perilaku bisnis, yang melibatkan beberapa aspek seperti & OK3 :risk-taking \\
& pengambilan risiko, inovasi dan proaktif. & OK4 :Agresivitas \\
(Pesämaa, 2007) & & kompetitif
\end{tabular}

Organisasi yang luas generasi intelijen pasar yang berkaitan OP1 : Orientasi

Orientasi Pasar dengan kebutuhan pelanggan saat ini dan masa depan, Pelanggan penyebaran intelijen secara horizontal dan vertikal dalam OP2 : Orientasi organisasi, dan tindakan organisasi yang luas atau responsif Pesaing

(Slater \& Narver, 2000)terhadapnya. OP3 : Koordinasi Antar Fungsi

\begin{tabular}{|c|c|}
\hline $\begin{array}{l}\text { Intellectual Capital } \\
\text { (Kamukama, Ahiauzu, } \\
\text { \& Ntayi, 2011); } \\
\text { (Todericiu \& Stăniţ, } \\
\text { 2015); (Kamukama, } \\
\text { 2013) }\end{array}$ & $\begin{array}{l}\text { Modal intelektual juga didefinisikan sebagai total stokIC1: Keterampilan } \\
\text { semua aset dan kemampuan tidak berwujud dalamkaryawan } \\
\text { perusahaan yang dapat menciptakan nilai. Stewart (1994)IC2: Kualifikasi } \\
\text { mendefinisikan modal intelektual sebagai total stok kolektifkaryawan } \\
\text { pengetahuan, informasi, teknologi, hak kekayaan intelektual,IC3: Pengetahuan } \\
\text { pengalaman, pembelajaran dan kompetensi organisasi,karyawan } \\
\text { sistem komunikasi tim, hubungan pelanggan, dan merekIC4 : Pengalaman } \\
\text { yang mampu menciptakan nilai-nilai untuk suatu perusahaankaryawan }\end{array}$ \\
\hline $\begin{array}{l}\text { Inovasi Produk } \\
\text { (Dwiyono, 2006) }\end{array}$ & $\begin{array}{l}\text { Inovasi produk yang baik memberikan berbagai manfaatIP1 : Perluasan } \\
\text { bagi organisasi, seperti meningkatkan posisi pasar, merek,Lini Produk } \\
\text { menarik konsumen baru dan meningkatkan loyalitasIP2 : Produk } \\
\text { konsumen.Industri kreatif tidak hanya memiliki tingkatTiruan } \\
\text { kapasitas inovatif yang tinggi tetapi juga dapat membentukIP3 : Produk Baru } \\
\text { lingkungan yang dapat mendukung ide-ide kreatif dan } \\
\text { membantu dalam membuat produk, proses atau sistem baru }\end{array}$ \\
\hline
\end{tabular}

$\underline{\text { Variabel }}$

Keunggulan Bersaing

(Chan et al., 2004); (Porter, 1985)

\begin{tabular}{|c|c|}
\hline Definisi Operasional Variabel & I Indikator \\
\hline Berdasarkan teori keunggulan & KB1 :Keunggulan Biaya \\
\hline kompetitif, keunggulan & KB2 : Variasi produk yang \\
\hline kompetitif terdiri dari dua & ditawarkan \\
\hline dimensi utama, yaitu & KB3 : Kemampuan \\
\hline keunggulan biaya rendah dan & memanfaatkan sumber daya \\
\hline keunggulan diferensiasi sebagai & i KB4 : Kemampuan \\
\hline kunci dalam mencapai kineria & beradaptasi \\
\hline superior (Porter, 1985) & \\
\hline Baik buruknya kinerja & KBI1: Pertumbuhan Laba \\
\hline perusahaan sangat dipengaruhi & KBI2: Pertumbuhan \\
\hline oleh kemampuan perusahaan & Penjualan \\
\hline untuk menggunakan sumber & KBI3: Pertumbuhan \\
\hline
\end{tabular}




\begin{tabular}{ll}
\hline 2017) & perubahan kondisi inovasi. KBI4 : Penganggaran \\
& Jaugh dan Glueck (1998) \\
& menyatakan bahwa pengukuran \\
& kinerja perusahaan dapat dilihat \\
& dari tingkat penjualan, \\
profitabilitas, pengembalian & \\
modal, tingkat turnover, dan & \\
pangsa pasar. & \\
\hline
\end{tabular}

Teknik analisis data pada penelitian ini adalah kuantitatif, penelitian ini di desain dengan data statistik. Pendekatan yang digunakan adalah Structural Equation Modelling Partial Least Square (SEM-PLS) dengan aplikasi software Smart PLS.

\section{Hasil dan Pembahasan}

Penelitian ini adalah adalah pemilik atau yang bertanggung jawab dalam kegiatan UMKM Batik yang berada di Kota Semarang yang berjumlah berjumlah 30 orang, yang diperoleh dari hasil penentuan sampel dengan metode sampling sensus, yaitu sampel yang digunakan adalah keseluruhan jumlah populasi. Hasil penelitian ini sebagai berikut:

\section{A. Hasil Uji Validitas dan Reliabilitas}

Outer model merupakan model yang menspesifikasi hubungan antara variable laten dengan indikator-indikatornya atau bisa dikatakan bahwa outer model mendefinisikan bagaimana setiap indikator berhubungan dengan variabel latennya. Pengujian outer model dalam penelitian ini menggunakan uji nilai konvergennya (convergent validity), discriminant validity dan composite reliability. Adapun hasil pengujian outer model dapat diketahui sebagai berikut :

\section{Nilai Konvergennya (Convergent Validity)}

Pengujian dalam menilai convergent validity didasarkan atas korelasi antara item score/component score. Ukuran refleksif individual dikatakan tinggi jika berkorelasi lebih dari 0.70 dengan konstruk yang diukur. Namun untuk penelitian tahap awal dari pengembangan skala pengukuran nilai loading 0.5 sampai 0.6 dianggap cukup memadai. Adapun batas nilai loading factor yang digunakan dalam penelitian adalah 0.60. Artinya apabila tiap-tiap indikator memiliki nilai loading factor lebih dari 0,6, maka indikator tersebut telah memenuhi validitas konvergen (convergent validity) dan sebaliknya. Untuk melihat nilai loading factor dari indikator-indikator yang mengukur konstruk dapat diketahui dari gambar berikut:

Discriminant validity pada suatu model dianggap baik jika setiap nilai loading dari setiap indikator dari sebuah variabel laten memiliki nilai loading yang paling besar dengan nilai loading lain terhadap variabel laten lainnya. Hasil pengujian discriminant validity diperoleh sebagai berikut: 


\section{Tabel 4}

Pengujian Discriminant Validity

\begin{tabular}{|c|c|c|c|c|}
\hline & $\begin{array}{l}\text { original } \\
\text { sample } \\
\text { estimate }\end{array}$ & $\begin{array}{c}\text { mean of } \\
\text { subsamples }\end{array}$ & $\begin{array}{l}\text { Standard } \\
\text { deviation }\end{array}$ & $\begin{array}{c}\mathrm{T}- \\
\text { Statistic }\end{array}$ \\
\hline OK1 & 0.687 & 0.707 & 0.122 & 5.648 \\
\hline $\mathrm{OK} 2$ & 0.698 & 0.738 & 0.086 & 8.120 \\
\hline $\mathrm{OK} 3$ & 0.902 & 0.897 & 0.020 & 44.124 \\
\hline OK4 & 0.743 & 0.761 & 0.057 & 12.919 \\
\hline OK5 & 0.839 & 0.818 & 0.053 & 15.910 \\
\hline OK6 & 0.808 & 0.766 & 0.074 & 10.925 \\
\hline OK7 & 0.702 & 0.684 & 0.129 & 5.444 \\
\hline OK8 & 0.711 & 0.705 & 0.076 & 9.317 \\
\hline OP1 & 0.847 & 0.826 & 0.067 & 12.666 \\
\hline OP2 & 0.805 & 0.786 & 0.073 & 11.002 \\
\hline OP3 & 0.628 & 0.621 & 0.133 & 4.724 \\
\hline OP4 & 0.863 & 0.851 & 0.021 & 40.518 \\
\hline OP5 & 0.905 & 0.902 & 0.020 & 44.735 \\
\hline OP6 & 0.769 & 0.733 & 0.077 & 10.005 \\
\hline IC1 & 0.613 & 0.536 & 0.145 & 4.221 \\
\hline $\mathrm{IC} 2$ & 0.741 & 0.711 & 0.122 & 6.052 \\
\hline IC3 & 0.684 & 0.651 & 0.121 & 5.635 \\
\hline IC4 & 0.677 & 0.674 & 0.113 & 6.004 \\
\hline IC5 & 0.692 & 0.767 & 0.126 & 5.487 \\
\hline IC6 & 0.857 & 0.854 & 0.037 & 22.982 \\
\hline IC7 & 0.844 & 0.844 & 0.036 & 23.672 \\
\hline IC8 & 0.762 & 0.780 & 0.066 & 11.465 \\
\hline IP1 & 0.772 & 0.727 & 0.078 & 9.867 \\
\hline IP2 & 0.842 & 0.839 & 0.072 & 11.614 \\
\hline IP3 & 0.616 & 0.689 & 0.146 & 4.211 \\
\hline IP4 & 0.705 & 0.681 & 0.110 & 6.418 \\
\hline IP5 & 0.934 & 0.941 & 0.014 & 64.978 \\
\hline IP6 & 0.864 & 0.875 & 0.067 & 12.979 \\
\hline KB1 & 0.715 & 0.773 & 0.053 & 13.482 \\
\hline KB2 & 0.653 & 0.683 & 0.074 & 8.827 \\
\hline KB3 & 0.846 & 0.820 & 0.037 & 22.621 \\
\hline KB4 & 0.773 & 0.782 & 0.060 & 12.772 \\
\hline
\end{tabular}




\begin{tabular}{lllll}
\hline KB5 & 0.706 & 0.735 & 0.065 & 10.799 \\
\hline KB6 & 0.809 & 0.813 & 0.059 & 13.733 \\
\hline KB7 & 0.771 & 0.793 & 0.112 & 6.891 \\
\hline KB8 & 0.684 & 0.739 & 0.111 & 6.167 \\
\hline KBB1 & 0.740 & 0.769 & 0.077 & 9.613 \\
\hline KBB2 & 0.788 & 0.812 & 0.099 & 7.926 \\
\hline KBB3 & 0.780 & 0.714 & 0.085 & 9.201 \\
\hline KBB4 & 0.789 & 0.806 & 0.047 & 16.788 \\
\hline KBB5 & 0.634 & 0.695 & 0.093 & 6.842 \\
\hline KBB6 & 0.873 & 0.839 & 0.038 & 22.762 \\
\hline
\end{tabular}

Tabel 4 menunjukkan bahwa seluruh indikator memiliki nilai outer loading $>0,6$ dan memiliki nilai t-statistik > 1,96. Artinya bahwa bahwa semua indikator yang mengukur kontruk telah memenuhi validitas konvergen (convergent validity). Oleh karena seluruh indikator yang mengukur kontruk telah memenuhi convergent validity, sehingga dapat digunakan dalam pengujian hipotesis.

\section{Nilai Diskriminannya (Discriminant Validity)}

Discriminant validity pada suatu model dianggap baik jika setiap nilai loading dari setiap indikator dari sebuah variabel laten memiliki nilai loading yang paling besar dengan nilai loading lain terhadap variabel laten lainnya. Hasil pengujian discriminant validity diperoleh sebagai berikut :

Tabel 5

\begin{tabular}{ccccccc}
\multicolumn{6}{c}{ Hasil Pengujian } & Discriminant Validity \\
\hline & OK & OP & IC & IP & KB & KBB \\
\hline IC1 & 0.293 & 0.421 & 0.613 & 0.328 & 0.384 & 0.454 \\
\hline IC2 & 0.516 & 0.582 & 0.741 & 0.490 & 0.632 & 0.662 \\
\hline IC3 & 0.461 & 0.511 & 0.684 & 0.431 & 0.507 & 0.610 \\
\hline IC4 & 1.029 & 0.666 & 0.677 & 0.587 & 0.869 & 0.870 \\
\hline IC5 & 0.861 & 0.522 & 0.692 & 0.486 & 0.729 & 0.736 \\
\hline IC6 & 0.750 & 0.774 & 0.857 & 0.580 & 0.838 & 0.818 \\
\hline IC7 & 0.646 & 0.662 & 0.844 & 0.527 & 0.750 & 0.734 \\
\hline IC8 & 0.466 & 0.505 & 0.762 & 0.449 & 0.550 & 0.556 \\
\hline IP1 & 0.616 & 0.699 & 0.726 & 0.772 & 0.679 & 0.691 \\
\hline
\end{tabular}


Analisis Faktor-Faktor yang Mempengaruhi Keunggulan Bersaing terhadap Kinerja Bisnis (Studi pada UMKM Batik di Kota Semarang)

\begin{tabular}{|c|c|c|c|c|c|c|}
\hline IP2 & 0.612 & 0.684 & 0.945 & 0.842 & 0.773 & 0.824 \\
\hline IP3 & 0.927 & 0.519 & 0.616 & 0.616 & 0.683 & 0.646 \\
\hline IP4 & 0.434 & 0.451 & 0.591 & 0.705 & 0.537 & 0.535 \\
\hline IP5 & 1.000 & 0.924 & 1.028 & 0.934 & 0.996 & 0.960 \\
\hline IP6 & 0.869 & 0.729 & 0.788 & 0.864 & 0.809 & 0.787 \\
\hline KB1 & 1.091 & 0.550 & 0.839 & 0.610 & 0.715 & 0.849 \\
\hline KB2 & 1.019 & 0.590 & 0.707 & 0.573 & 0.653 & 0.750 \\
\hline KB3 & 0.701 & 0.706 & 0.885 & 0.572 & 0.846 & 0.789 \\
\hline KB4 & 0.681 & 0.766 & 0.806 & 0.626 & 0.773 & 0.758 \\
\hline KB5 & 0.627 & 0.710 & 0.742 & 0.423 & 0.706 & 0.700 \\
\hline KB6 & 0.839 & 0.765 & 0.936 & 0.689 & 0.809 & 0.854 \\
\hline B7 & 0.730 & 0.719 & 0.870 & 0.556 & 0.771 & 0.842 \\
\hline KB8 & 0.801 & 0.680 & 0.646 & 0.470 & 0.684 & 0.678 \\
\hline BB1 & 0.623 & 0.647 & 0.841 & 0.587 & 0.784 & 0.740 \\
\hline KBB2 & 0.886 & 0.618 & 0.855 & 0.524 & 0.762 & 0.788 \\
\hline KBB3 & 0.638 & 0.675 & 0.799 & 0.491 & 0.700 & 0.780 \\
\hline KBB4 & 0.886 & 0.919 & 0.955 & 0.643 & 0.959 & 0.789 \\
\hline KBB5 & 0.934 & 0.533 & 0.752 & 0.660 & 0.743 & 0.634 \\
\hline KBB6 & 0.735 & 0.727 & 0.871 & 0.559 & 0.802 & 0.873 \\
\hline OK1 & 0.687 & 0.378 & 0.508 & 0.389 & 0.592 & 0.548 \\
\hline OK2 & 0.698 & 0.485 & 0.602 & 0.438 & 0.793 & 0.654 \\
\hline OK3 & 0.902 & 0.824 & 0.972 & 0.686 & 1.026 & 0.957 \\
\hline OK4 & 0.743 & 0.911 & 1.020 & 0.851 & 0.928 & 0.936 \\
\hline OK5 & 0.839 & 0.722 & 0.774 & 0.573 & 0.869 & 0.806 \\
\hline OK6 & 0.808 & 0.617 & 0.601 & 0.414 & 0.705 & 0.695 \\
\hline
\end{tabular}




\begin{tabular}{ccccccc}
\hline OK7 & 0.702 & 0.806 & 0.831 & 0.613 & 0.757 & 0.823 \\
\hline OK8 & 0.711 & 0.552 & 0.858 & 0.448 & 0.766 & 0.778 \\
\hline OP1 & 0.704 & 0.847 & 0.721 & 0.506 & 0.685 & 0.643 \\
\hline OP2 & 0.557 & 0.805 & 0.691 & 0.557 & 0.661 & 0.646 \\
\hline OP3 & 0.800 & 0.628 & 0.676 & 0.488 & 0.671 & 0.682 \\
\hline OP4 & 0.962 & 0.863 & 1.008 & 0.710 & 1.006 & 0.998 \\
\hline OP5 & 0.914 & 0.905 & 0.969 & 0.662 & 0.930 & 0.926 \\
\hline OP6 & 0.567 & 0.769 & 0.726 & 0.476 & 0.694 & 0.642 \\
\hline
\end{tabular}

Sumber : Data primer yang diolah

Tabel 5 menunjukkan bahwa seluruh indikator pada variabel orientasi kewirausahaan, orientasi pasar, intellectual capital, innovasi produk, keunggulan bersaing dan kinerja bisnis memiliki nilai loading factor lebih besar dibanding nilai loading variabel laten lain. Hasil ini menunjukkan bahwa Artinya, variabel orientasi kewirausahaan, orientasi pasar, intellectual capital, innovasi produk, keunggulan bersaing dan kinerja bisnis memiliki nilai discriminant validity yang baik. Pengujian discriminant validity juga dapat dilakukan dengan melihat nilai average variance extracted (AVE) untuk setiap konstruk. Adapun hasil discriminant validity dapat dilihat pada tabel 6 berikut:

Tabel 6

Average Variance Extracted (AVE)

\begin{tabular}{lc} 
& Average Variance Extracted (AVE) \\
\hline & Average variance extracted (AVE) \\
\hline $\mathrm{OK}$ & 0.585 \\
\hline $\mathrm{OP}$ & 0.653 \\
\hline $\mathrm{IC}$ & 0.545 \\
\hline $\mathrm{IP}$ & 0.633 \\
\hline $\mathrm{KB}$ & 0.558 \\
\hline $\mathrm{KBB}$ & 0.594 \\
\hline & Sumber : Data primer yang diolah
\end{tabular}

Tabel 6 menunjukkan bahwa diperoleh nilai average variance extracted (AVE) untuk konstruk variabel orientasi kewirausahaan diketahui sebesar 0,585, nilai AVE untuk variabel orientasi pasar diketahui sebesar 0,653, nilai AVE variabel intellectual capital diketahui sebesar 0,558, nilai AVE variabel innovasi produk diketahui sebesar 0,633, nilai AVE variabel keunggulan bersaing diketahui sebesar 0,558 dan nilai AVE variabel kinerja bisnis diketahui sebesar 0,594 . Oleh karena seluruh konstruk memiliki nilai average variance extracted 
(AVE) lebih besar dari 0, maka dapat disimpulkan bahwa model dalam penelitian ini telah memiliki discriminant validity yang baik.

\section{Composite Reliability}

Composite reliability menguji nilai reliabilitas antara blok indicator dari konstruk yang membentuknya. Adapun hasil output composite reliability dapat diketahui pada tabel 7 berikut ini:

Tabel 7

Hasil Composite Reliability

\begin{tabular}{cc}
\hline & $\begin{array}{c}\text { Composite } \\
\text { Reliability }\end{array}$ \\
\hline $\mathrm{OK}$ & 0.918 \\
\hline $\mathrm{OP}$ & 0.918 \\
\hline $\mathrm{IC}$ & 0.904 \\
\hline $\mathrm{IP}$ & 0.911 \\
\hline $\mathrm{KB}$ & 0.909 \\
\hline KBB & 0.897 \\
\hline
\end{tabular}

Tabel 7 menunjukkan bahwa diperoleh bahwa variabel orientasi kewirausahaan memiliki nilai composite reliability sebesar 0,918, variabel orientasi pasar memiliki nilai composite reliability sebesar 0,918, variabel intellectual capital memiliki nilai composite reliability sebesar 0,904, variabel inovasi produk memiliki nilai composite reliability sebesar 0,911, variabel keunggulan bersaing memiliki nilai composite reliability sebesar 0,909 dan variabel kinerja bisnis memiliki nilai composite reliability sebesar 0,897 . Hasil ini menunjukkan bahwa seluruh variabel memiliki nilai composite reliability yang lebih besar dari 0,70 . Dengan demikian model dalam penelitian ini telah memenuhi composite reliability.

\section{Pengujian Model Struktural (Inner Model )}

Pengujian inner model atau model struktural dilakukan untuk melihat antar konstruk, nilai signifikansi dan R-square dari model penelitian. Model struktural dievaluasi dengan menggunakan R-square dengan konstruk dependen uji t serta signifikandi koefisien parameter jalur struktural. Dalam menilai model dengan PLS dimulai dengan melihat $R$-square untuk setiap variabel laten dependen. Estimasi $R$-square dapat ditunjukkan pada tabel berikut: 
Tabel 8

Nilai R-square Model

\begin{tabular}{ll}
\hline & R-square \\
\hline OK & \\
\hline OP & \\
\hline IC & \\
\hline IP & \\
\hline KB & 0.933 \\
\hline KBB & 0.955 \\
\hline
\end{tabular}

Sumber: Data primer yang diolah

\section{Pengujian Hipotesis}

Pengujian hipotesis dan hubungan antar variabel dapat dilihat dari hasil Inner Weight pada model. Adapun hasil koefisien pada pengujian model struktural path dapat diketahui pada hasil inner model berikut ini:

Tabel 9

Hasil Inner Weight

\begin{tabular}{lcccc}
\hline & $\begin{array}{c}\text { original } \\
\text { sample } \\
\text { estimate }\end{array}$ & $\begin{array}{c}\text { mean of } \\
\text { subsamples }\end{array}$ & $\begin{array}{c}\text { Standard } \\
\text { deviation }\end{array}$ & T-Statistic \\
\hline OK -> KB & 0.331 & 0.411 & 0.076 & 4.365 \\
\hline OP -> KB & 0.218 & 0.159 & 0.103 & 2.124 \\
\hline IC -> KB & 0.366 & 0.375 & 0.157 & 2.334 \\
\hline IP -> KB & 0.125 & 0.089 & 0.139 & 0.902 \\
\hline OK -> KBB & 0.109 & 0.094 & 0.136 & 0.801 \\
\hline OP -> KBB & 0.034 & 0.082 & 0.154 & 0.218 \\
\hline IC -> KBB & 0.408 & 0.421 & 0.161 & 2.539 \\
\hline IP -> KBB & 0.048 & 0.047 & 0.162 & 0.298 \\
\hline KB -> KBB & 0.417 & 0.374 & 0.151 & 2.756 \\
\hline
\end{tabular}

Sumber : Data primer yang diolah

a) Pengujian Hipotesis 1

Hasil estimasi inner weight pada pengujian pengaruh orientasi kewirausahaan terhadap keunggulan bersaing diperoleh koefisien jalur sebesar 0,331 dan nilai t-statistics sebesar 4,365. Oleh karena nilai tstatistics lebih besar dari 1,96 (>1,96), maka dapat diketahui Ho ditolak dan H1 diterima. Sehingga dapat disimpulkan bahwa orientasi kewirausahaan berpengaruh signifikan terhadap keunggulan bersaing pada pemilik UMKM Batik di Kota Semarang.

b) Pengujian Hipotesis 2

Hasil estimasi inner weight pada pengujian pengaruh orientasi pasar terhadap keunggulan bersaing diperoleh koefisien jalur sebesar 0,218 dan 
nilai t-statistics sebesar 2,124. Oleh karena nilai t-statistics lebih besar dari 1,96 (>1,96), maka dapat diketahui Ho ditolak dan H2 diterima. Sehingga dapat disimpulkan bahwa orientasi pasar berpengaruh signifikan terhadap keunggulan bersaing pada pemilik UMKM Batik di Kota Semarang.

c) Pengujian Hipotesis 3

Hasil estimasi inner weight pada pengujian pengaruh intellectual capital terhadap keunggulan bersaing diperoleh koefisien jalur sebesar 0,366 dan nilai t-statistics sebesar 2,334. Oleh karena nilai t-statistics lebih besar dari 1,96 (>1,96), maka dapat diketahui Ho ditolak dan H3 diterima. Sehingga dapat disimpulkan bahwa intellectual capital berpengaruh signifikan terhadap keunggulan bersaing pada pemilik UMKM Batik di Kota Semarang.

d) Pengujian Hipotesis 4

Hasil estimasi inner weight pada pengujian pengaruh inovasi produk terhadap keunggulan bersaing diperoleh koefisien jalur sebesar 0,125 dan nilai t-statistics sebesar 0,902. Oleh karena nilai t-statistics lebih kecil dari 1,96 (<1,96), maka dapat diketahui Ho diterima dan H4 ditolak. Sehingga dapat disimpulkan bahwa orientasi produk tidak berpengaruh signifikan terhadap keunggulan bersaing pada pemilik UMKM Batik di Kota Semarang.

e) Pengujian Hipotesis 5

Hasil estimasi inner weight pada pengujian pengaruh orientasi kewirausahaan terhadap kinerja bisnis diperoleh koefisien jalur sebesar 0,109 dan nilai t-statistics sebesar 0,801 . Oleh karena nilai t-statistics lebih kecil dari 1,96 $(<1,96)$, maka dapat diketahui Ho diterima dan H5 ditolak. Sehingga dapat disimpulkan bahwa orientasi kewirausahaan berpengaruh signifikan terhadap kinerja bisnis pada pemilik UMKM Batik di Kota Semarang.

f) Pengujian Hipotesis 6

Hasil estimasi inner weight pada pengujian pengaruh orientasi pasar terhadap kinerja bisnis diperoleh koefisien jalur sebesar 0,034 dan nilai tstatistics sebesar 0,218. Oleh karena nilai t-statistics lebih kecil dari 1,96 $(<1,96)$, maka dapat diketahui Ho diterima dan H6 ditolak. Sehingga dapat disimpulkan bahwa orientasi pasar tidak berpengaruh signifikan terhadap kinerja bisnis pada pemilik UMKM Batik di Kota Semarang.

g) Pengujian Hipotesis 7

Hasil estimasi inner weight pada pengujian pengaruh intellectual capital terhadap kinerja bisnis diperoleh koefisien jalur sebesar 0,408 dan nilai t-statistics sebesar 2,539. Oleh karena nilai t-statistics lebih besar dari 1,96 (>1,96), maka dapat diketahui Ho ditolak dan H7 diterima. Sehingga dapat disimpulkan bahwa intellectual capital berpengaruh signifikan terhadap kinerja bisnis pada pemilik UMKM Batik di Kota Semarang. 
h) Pengujian Hipotesis 8

Hasil estimasi inner weight pada pengujian pengaruh inovasi produk terhadap kinerja bisnis diperoleh koefisien jalur sebesar 0,048 dan nilai tstatistics sebesar 0,298. Oleh karena nilai t-statistics lebih kecil dari 1,96 $(<1,96)$, maka dapat diketahui Ho diterima dan H8 ditolak. Sehingga dapat disimpulkan bahwa orientasi produk tidak berpengaruh signifikan terhadap kinerja bisnis pada pemilik UMKM Batik di Kota Semarang.

i) Pengujian Hipotesis 9

Hasil estimasi inner weight pada pengujian pengaruh keunggulan bersaing terhadap kinerja bisnis diperoleh koefisien jalur sebesar 0,417 dan nilai t-statistics sebesar 2,756. Oleh karena nilai t-statistics lebih besar dari 1,96 (>1,96), maka dapat diketahui Ho ditolak dan H9 diterima. Sehingga dapat disimpulkan bahwa keunggulan bersaing berpengaruh signifikan terhadap kinerja bisnis pada pemilik UMKM Batik di Kota Semarang.

\section{B. Uji Langsung dan Tidak Langsung}

Pengujian langsung dan tidak langsung dalam penelitian ini menguji pengaruh orientasi kewirausahaan, orientasi pasar, intellectual capital dan inovasi produk terhadap kinerja bisnis melalui keunggulan bersaing sebagai variabel intervening. Adapun hasil pengujian langsung dan tidak langsung dapat diketahui sebagai berikut:

\section{Uji Langsung dan Tidak Langsung Pengaruh Orientasi Kewirausahaan terhadap Kinerja Bisnis melalui Keunggulan Bersaing}

Hasil uji langsung dan tidak langsung pengaruh orientasi kewirausahaan terhadap kinerja bisnis melalui keunggulan bersaing sebagai variabel intervening dapat digambarkan berikut ini:

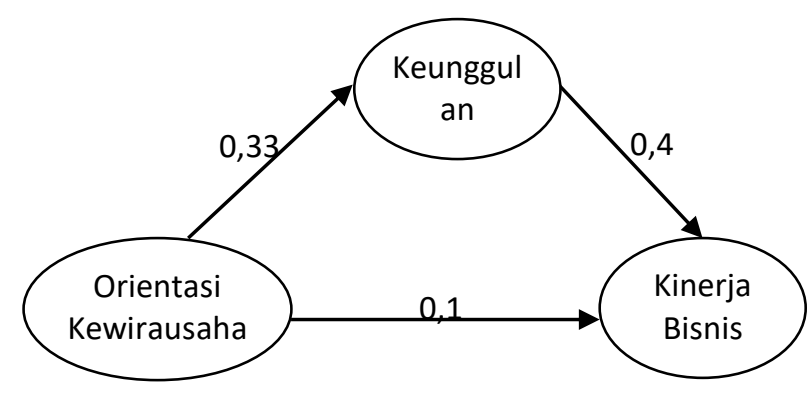

$$
\begin{array}{lll}
\text { Hubungan langsung } & = & 0,109 \\
\text { Hubungan tidak langsung } & = & 0,331 \times 0,417=0,138
\end{array}
$$

Gambar di atas menunjukkan hasil uji mediasi, dimana diperoleh hasil pengaruh tidak langsung sebesar 0,138. Hasil perhitungan tersebut menunjukkan bahwa hasil pengaruh tidak langsung diketahui lebih besar dari nilai pengaruh langsung sebesar 0,109. Dengan demikian dapat disimpulkan bahwa keunggulan bersaing mampu memediasi pengaruh orientasi kewirausahaan terhadap kinerja bisnis. 


\section{Uji Langsung dan Tidak Langsung Pengaruh Orientasi Pasar terhadap Kinerja Bisnis melalui Keunggulan Bersaing}

Hasil uji langsung dan tidak langsung pengaruh orientasi pasar terhadap kinerja bisnis melalui keunggulan bersaing sebagai variabel intervening dapat digambarkan berikut ini:

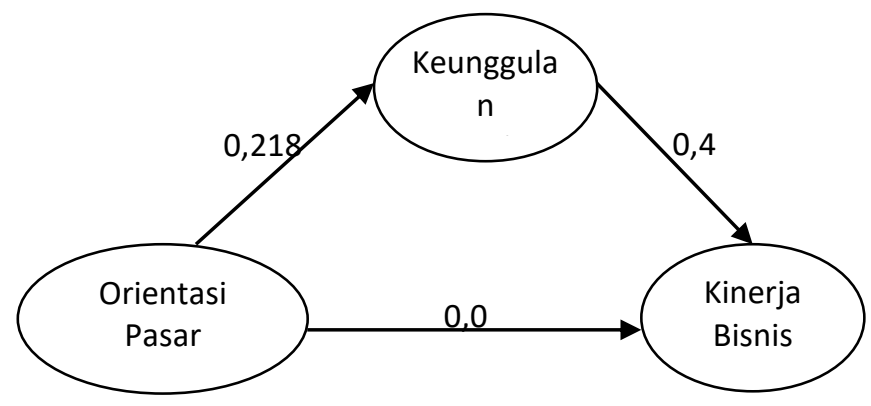

$\begin{array}{lll}\text { Hubungan langsung } & = & 0,034 \\ \text { Hubungan tidak langsung } & = & 0,218 \times 0,417=0,091\end{array}$

Gambar di atas menunjukkan hasil uji mediasi, dimana diperoleh hasil pengaruh tidak langsung sebesar 0,091. Hasil perhitungan tersebut menunjukkan bahwa hasil pengaruh tidak langsung diketahui lebih besar dari nilai pengaruh langsung sebesar 0,034. Dengan emikian dapat disimpulkan bahwa keunggulan bersaing mampu memediasi pengaruh orientasi pasar terhadap kinerja bisnis.

3. Uji Langsung dan Tidak Langsung Pengaruh Intellectual Capital terhadap Kinerja Bisnis melalui Keunggulan Bersaing

Hasil uji langsung dan tidak langsung pengaruh intellectual capital terhadap kinerja bisnis melalui keunggulan bersaing sebagai variabel intervening dapat digambarkan berikut ini:

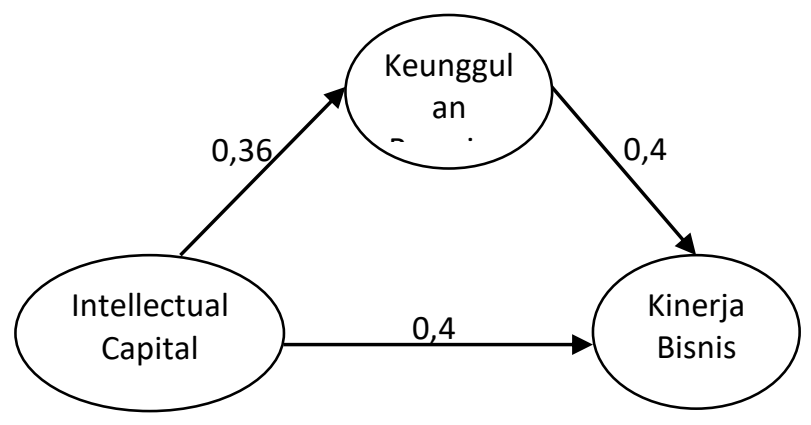

Hubungan langsung $\quad=\quad 0,153$

Hubungan tidak langsung $=0,366 \times 0,417=0,153$

Gambar di atas menunjukkan hasil uji mediasi, dimana diperoleh hasil pengaruh tidak langsung sebesar 0,153 . Hasil perhitungan tersebut menunjukkan bahwa hasil pengaruh tidak langsung diketahui lebih kecil dari nilai pengaruh langsung sebesar 0,408. Dengan demikian dapat disimpulkan bahwa keunggulan bersaing tidak mampu memediasi pengaruh intellectual capital terhadap kinerja bisnis. 


\section{Uji Langsung dan Tidak Langsung Pengaruh Inovasi Produk terhadap Kinerja Bisnis melalui Keunggulan Bersaing}

Hasil uji langsung dan tidak langsung pengaruh inovasi produk terhadap kinerja bisnis melalui keunggulan bersaing sebagai variabel intervening dapat digambarkan berikut ini :

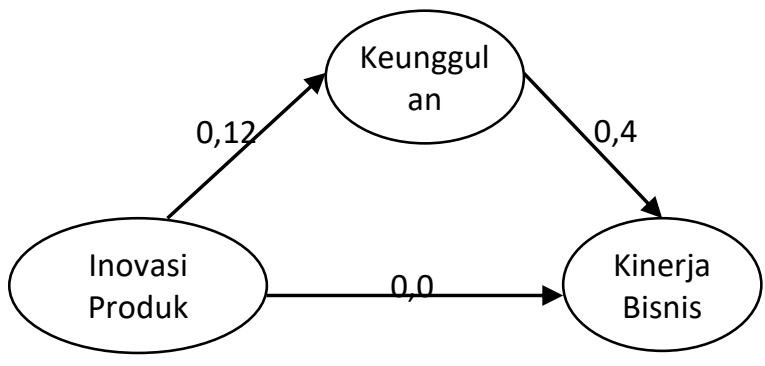

$$
\begin{array}{lll}
\text { Hubungan langsung } & = & 0,048 \\
\text { Hubungan tidak langsung } & = & 0,125 \times 0,417=0,052
\end{array}
$$

Gambar di atas menunjukkan hasil uji mediasi, dimana diperoleh hasil pengaruh tidak langsung sebesar 0,052. Hasil perhitungan tersebut menunjukkan bahwa hasil pengaruh tidak langsung diketahui lebih besar dari nilai pengaruh langsung sebesar 0,048. Dengan demikian dapat disimpulkan bahwa keunggulan bersaing mampu memediasi pengaruh intellectual capital terhadap kinerja bisnis.

\section{Kesimpulan}

Dari hasil pengujian hipotesis 1 yang berbunyi Orientasi Kewirausahaan diduga berpengaruh positif terhadap Keunggulan Bersaing menunjukkan nilai t statistic 4,365 yang lebih besar dari t table sebesar 1,96. Hasil pengujian tersebut membuktikan bahwa hipotesis 1 terbukti signifikan yaitu Orientasi Kewirausahaan berpengaruh positif signifikan terhadap Keunggulan Bersaing.

Dari hasil pengujian hipotesis 2 yang berbunyi Orientasi Pasar diduga berpengaruh positif terhadap Keunggulan Bersaing menunjukkan nilai t statistic 2,124 yang lebih besar dari $\mathrm{t}$ table sebesar 1,96. Hasil pengujian tersebut membuktikan bahwa hipotesis 2 terbukti signifikan yaitu Orientasi Pasar berpengaruh positif signifikan terhadap Keunggulan Bersaing.

Dari hasil pengujian hipotesis 3 yang berbunyi Intellectual capital diduga berpengaruh positif terhadap Keunggulan Bersaing menunjukkan nilai t statistic 2,334 yang lebih besar dari t table sebesar 1,96. Hasil pengujian tersebut membuktikan bahwa hipotesis 3 terbukti signifikan yaitu Intellectual capital berpengaruh positif signifikan terhadap Keunggulan Bersaing.

Dari hasil pengujian hipotesis 4 yang berbunyi Inovasi Produk diduga tidak berpengaruh positif terhadap Keunggulan Bersaing menunjukkan nilai t statistic 0,902. $(<1,96)$. Hasil pengujian tersebut membuktikan bahwa hipotesis 4 terbukti tidak 
berpengaruh signifikan yaitu Inovasi Produk tidak berpengaruh signifikan terhadap Keunggulan Bersaing.

Dari hasil pengujian hipotesis 5 yang berbunyi orientasi kewirausahaan diduga tidak berpengaruh positif terhadap kinerja bisnis menunjukkan nilai t statistic 0,801 ( < 1,96). Hasil pengujian tersebut membuktikan bahwa hipotesis 5 terbukti tidak berpengaruh signifikan yaitu orientasi kewirausahaan tidak berpengaruh signifikan terhadap kinerja bisnis.

Dari hasil pengujian hipotesis 6 yang berbunyi Orientasi Pasar diduga tidak berpengaruh positif terhadap Kinerja Bisnis menunjukkan nilai t statistic 0,218. (< 1,96). Hasil pengujian tersebut membuktikan bahwa hipotesis 6 terbukti tidak berpengaruh signifikan yaitu Orientasi Pasar tidak berpengaruh signifikan terhadap Kinerja Bisnis.

Dari hasil pengujian hipotesis 7 yang berbunyi Intellectual capital diduga t berpengaruh positif terhadap Kinerja Bisnis menunjukkan nilai t statistic 2,539 (> 1,96). Hasil pengujian tersebut membuktikan bahwa hipotesis 7 terbukti berpengaruh signifikan yaitu Intellectual capital berpengaruh signifikan terhadap Kinerja Bisnis.

Dari hasil pengujian hipotesis 8 yang berbunyi Inovasi produk diduga t tidak berpengaruh positif terhadap Kinerja Bisnis menunjukkan nilai t statistic 0,298 $(<1,96)$. Hasil pengujian tersebut membuktikan bahwa hipotesis 8 terbukti tidak berpengaruh signifikan yaitu Inovasi produk tidak berpengaruh signifikan terhadap Kinerja Bisnis.

Dari hasil pengujian hipotesis 9 yang Keunggulan Bersaing diduga $t$ berpengaruh positif terhadap Kinerja Bisnis menunjukkan nilai t statistic 2,756 (> 1,96). Hasil pengujian tersebut membuktikan bahwa hipotesis 9 terbukti berpengaruh signifikan yaitu intellectual capital berpengaruh signifikan terhadap kinerja bisnis. 


\section{BIBLIOGRAFI}

Asyhari, Asyhari, Pudjihastuti, Sri Hindah, \& Kurdaningsih, Dian Marhaeni. (2018). Peran mediasi keunggulan kompetitif pada faktor determinan kinerja bisnis UKM di sentra tenun batik di Jawa Tengah. Jurnal Siasat Bisnis, 22(2), 111-131. Google Scholar

Budiastuti, Dyah, \& Versia, Versia. (2011). Pengaruh Kapabilitas terhadap Keunggulan Kompetitif dan Dampaknya terhadap Kinerja Perusahaan pada PT Adi Cipta, Makassar. Binus Business Review, 2(1), 286-292. Google Scholar

Chan, Lismen L. M., Shaffer, Margaret A., \& Snape, Ed. (2004). In search of sustained competitive advantage: the impact of organizational culture, competitive strategy and human resource management practices on firm performance. The International Journal of Human Resource Management, 15(1), 17-35. Google Scholar

Chowdhury, Partha Prasad. (2013). Key strategies and issues of positioning: A review of past studies. American Academic \& Scholarly Research Journal, 5(1), 55. Google Scholar

Dwiyono, Teguh. (2006). Pengaruh Variasi Besar, Tinggi Gaya Tekan dan Kemiringan Pipa Output terhadap Head pada Alat Peraga Hukum Pascal untuk Menaikkan Elevasi Muka Air. Universitas Negeri Semarang. Google Scholar

Echdar, Saban. (2012). Maryadi. Bussines Ethics and Entrepeneurship. Yogyakarta. Google Scholar

Efrat, Kalanit, Hughes, Paul, Nemkova, Ekaterina, Souchon, Anne L., \& Sy-Changco, Joseph. (2018). Leveraging of Dynamic export capabilities for competitive advantage and performance consequences: Evidence from China. Journal of Business Research, 84, 114-124. Google Scholar

Hsu, Meng Hsiang, Ju, Teresa L., Yen, Chia Hui, \& Chang, Chun Ming. (2007). Knowledge sharing behavior in virtual communities: The relationship between trust, self-efficacy, and outcome expectations. International Journal of HumanComputer Studies, 65(2), 153-169. Google Scholar

Ismail, Daud, Alam, Syed Shah, \& Hamid, Roshayati bt Abdul. (2017). Trust, commitment, and competitive advantage in export performance of SMEs. Gadjah Mada International Journal of Business, 19(1), 1-18. Google Scholar

Ismail, Tubagus. (2012). The development of entrepreneurial social competence and business network to improve competitive advantage and business performance of small medium sized enterprises: A case study of batik industry in Indonesia. Procedia-Social and Behavioral Sciences, 65, 46-51. Google Scholar

Ismanu, Sidik, \& Kusmintarti, Anik. (2018). Pengaruh Lingkungan Industri Terhadap Kinerja Perusahaan Melalui Inovasi Sebagai Variabel Mediasi (Studi Kasus Di 
Analisis Faktor-Faktor yang Mempengaruhi Keunggulan Bersaing terhadap Kinerja Bisnis (Studi pada UMKM Batik di Kota Semarang)

Ukm Batik Tulis). Prosiding Seminar Nasional Akuntansi, Manajemen, Dan Keuangan, 1(1). Google Scholar

Kamukama, Nixon. (2013). Intellectual capital: company's invisible source of competitive advantage. Competitiveness Review: An International Business Journal. Google Scholar

Kamukama, Nixon, Ahiauzu, Augustine, \& Ntayi, Joseph M. (2011). Competitive advantage: mediator of intellectual capital and performance. Journal of Intellectual Capital. Google Scholar

Nkundabanyanga, Stephen Korutaro, Akankunda, Brendah, Nalukenge, Irene, \& Tusiime, Immaculate. (2017). The impact of financial management practices and competitive advantage on the loan performance of MFIs. International Journal of Social Economics. Google Scholar

Pesämaa, Ossi. (2007). Development of relationships in interorganizational networks: studies in the tourism and construction industries. Luleå tekniska universitet. Google Scholar

Porter, Michael E. (1985). Technology and competitive advantage. Journal of Business Strategy. Google Scholar

Rodan, Simon. (2008). Organizational learning: effects of (network) structure and (individual) strategy. Computational and Mathematical Organization Theory, 14(3), 222-247. Google Scholar

Slater, Stanley F., \& Narver, John C. (2000). The positive effect of a market orientation on business profitability: A balanced replication. Journal of Business Research, 48(1), 69-73. Google Scholar

Sugiyono, Prof. (2015). Metode penelitian kombinasi (mixed methods). Bandung: Alfabeta, 28. Google Scholar

Teece, David J., Pisano, Gary, \& Shuen, Amy. (1997). Dynamic capabilities and strategic management. Strategic Management Journal, 18(7), 509-533. Google Scholar

Todericiu, Ramona, \& Stăniţ, Alexandra. (2015). Intellectual capital-The key for sustainable competitive advantage for the SME's sector. Procedia Economics and Finance, 27, 676-681. Google Scholar

\section{Copyright holder:}

Mohamad Ari Wibowo dan Susilo Toto Raharjo (2021)

\section{First publication right:}


Mohamad Ari Wibowo dan Susilo Toto Raharjo

Journal Syntax Literate

This article is licensed under:

(c) ${ }_{\mathrm{EY}} \ominus_{\mathrm{ND}}$ 